\title{
Outcome in conversion disorder: a follow up study
}

\author{
W Couprie, E F M Wijdicks, H G M Rooijmans, J van Gijn
}

\begin{abstract}
Fifty six patients who had been admitted with a conversion disorder other than pseudoseizures were interviewed; mostly by telephone. The median interval was 4.5 years. If a patient had improved during a stay in hospital the eventual outcome was good in $96 \%$, against only $30 \%$ in the others (risk ratio $3 \cdot 2$ (95\% CI 1.8-5.6)). Rapid improvement was, in turn, related to recent onset of the symptoms. Two patients (4\%) subsequently developed an organic deficit that, in retrospect, might be related to the initial episode.
\end{abstract}

(F Neurol Neurosurg Psychiatry 1995;58:750-752)

Keywords: conversion disorder; outcome

A conversion disorder is a loss or alteration in sensory or voluntary motor function that cannot be explained by a physical disorder, but that more or less resembles the manifestations of structural disease of the nervous system. Most patients will have paralysis, anaesthesia, disturbed balance, aphonia, or blindness as a single symptom. In previous studies the incidence of subsequent organic (often neurological) disease that, in retrospect, explained the initial symptoms was unexpectedly high, between 13 and $34 \% .{ }^{1-7}$

Apart from the pitfall of misdiagnosis, opinions differ about the long term outcome of conversion disorders. Some studies conclude that the prognosis is good, but in others the results are far more pessimistic. ${ }^{2389}$ Factors associated with a favourable outcome in previous studies are acute onset of symptoms, precipitation by a stressful event, good premorbid health, and absence of organic disease or a concomitant psychiatric disorder.

The purpose of this study was twofold; firstly, to determine the incidence of subsequent neurological disease in patients in whom a functional disorder was diagnosed; secondly, to assess long term outcome as well as predictive factors for this outcome.

\section{Methods}

The medical records of all patients admitted from 1982 to 1989 to the University Department of Neurology in Utrecht were reviewed. Patients were referred to the department by primary care physicians and by neurologists in general hospitals. We collected patients with a discharge diagnosis of functional or hysterical disorder. All patients underwent appropriate physical examination and ancillary investigations to exclude organic disease. Patients with pseudoseizures were excluded from the study because these often coexist with epileptic fits. We also excluded patients with a history of neurological disease. In this way we identified 60 patients with a presumptive diagnosis of conversion disorder. Two patients were lost to follow up and two patients had died, one from unrelated disease and one by suicide. During the stay in hospital treatment consisted of reassurance and exercises. On discharge patients had usually been referred back to the general practitioner; sometimes rehabilitation specialists were also involved.

The 56 patients in the study were interviewed by one of us (WC) to gain information about the physical condition of the patients. We did not explicitly enquire after psychiatric symptoms but concentrated on overall performance and the degree of dependence. Twenty two patients were seen in the outpatient clinic. Thirty four patients who did not consent to a hospital visit were extensively interviewed by telephone; the information obtained by telephone was subsequently checked with the family physician.

To classify the degree of dependence of the patients we used the Oxford handicap scale (modified Rankin scale). ${ }^{10}$ We defined good condition as either grade 0 or grade 1 on the Oxford handicap scale (table 1). The condi-

\begin{tabular}{|c|c|}
\hline Grade & Description \\
\hline 0 & No symptoms \\
\hline 1 & $\begin{array}{l}\text { Minor symptoms that do not interfere with } \\
\text { lifestyle }\end{array}$ \\
\hline 2 & $\begin{array}{l}\text { Minor handicap, symptoms that lead to some } \\
\text { restriction in lifestyle but do not interfere with the } \\
\text { patient's capacity to be independent }\end{array}$ \\
\hline 3 & $\begin{array}{l}\text { Moderate handicap, symptoms that significantly } \\
\text { restrict lifestyle and prevent totally independent } \\
\text { existence }\end{array}$ \\
\hline 4 & $\begin{array}{l}\text { Moderately severe handicap, symptoms that } \\
\text { clearly prevent independent existence although } \\
\text { patient does not need constant attention }\end{array}$ \\
\hline 5 & $\begin{array}{l}\text { Severe handicap, totally dependent patient } \\
\text { requiring constant attention }\end{array}$ \\
\hline
\end{tabular}


tion on discharge was retrospectively established from the case notes of the attending physicians and nursing staff. Before the analysis we arbitrarily dichotomised age as a prognostic factor at below or above 40 , because we assumed no major changes in personality structure occur after that age. The occurrence of any stressful life events was recorded during the initial admission. Relative risks were estimated to compare outcome of patients with and without a given characteristic; $95 \%$ confidence intervals (95\% CIs) were used; a two tailed $p$ value $<0.05$ was considered statistically significant. Logistic regression was used to determine the independent contribution of the baseline characteristics to the prediction of outcome at follow up.

\section{Results}

The median age of the 56 patients at time of admission was 36 (range 15-73) years. Thirty six were women and 20 were men. The period between admission and the follow up interview ranged between 1.5 and 9.5 years (median follow up 4.5 years).

Forty one patients (73\%) had weakness in one or more limbs, often associated with sensory deficits or abnormal sensations. Seven patients $(12 \%)$ showed a gait disorder without weakness of separate muscle groups. Three patients $(5 \%)$ had a pure sensory deficit. Three patients (5\%) had aphonia, one $(2 \%)$ acute blindness, and one $(2 \%)$ torticollis.

In 33 patients (59\%) the onset of the conversion symptoms was recent, at most a few days before admission. Of these 33 patients, 24 had never manifested a conversion disorder before; eight patients had had the same conversion symptom and one patient another conversion symptom earlier in life. In the 23 patients $(41 \%)$ in whom the conversion symptom had existed for more than a few days, this was less than a year in 11 patients

Table 2 Degree of dependence (modified Rankin scale, or Oxford handicap scale) of 54 patients with "pure" conversion disorder, at discharge, and at follow up

\begin{tabular}{lllllll}
\hline & \multicolumn{7}{c}{ Condition at follow up } & & & \\
\cline { 2 - 7 } & Grade 0 & Grade 1 & Grade 2 & Grade 3 & Grade 4 & Grade 5 \\
\hline Condition at discharge & 15 & & & & 1 & \\
$\quad$ Grade 0 & 4 & 4 & & & & \\
Grade 1 & 3 & 4 & 3 & & 2 & \\
Grade 2 & 1 & 1 & 1 & 7 & 2 & 2 \\
Grade 3 & & & 1 & 1 & & 2 \\
Grade 4 & & & & & & \\
\hline Grade 5
\end{tabular}

Table 3 Influence of different characteristics on the degree of dependence at follow up of the 54 patients with "pure" conversion disorder: patients with good outcome at follow up

\begin{tabular}{lrll}
\hline Characteristic & \multicolumn{1}{l}{ Present } & Absent & Risk ratio (95\% CI) \\
\hline Age $>40$ years & $8 / 19(42 \%)$ & $24 / 35(69 \%)$ & $0 \cdot 6(0 \cdot 4-1 \cdot 1)$ \\
Male sex & $12 / 19(63 \%)$ & $20 / 35(57 \%)$ & $1 \cdot 1(0 \cdot 7-1 \cdot 7)$ \\
Previous episode of & $6 / 13(46 \%)$ & $26 / 41(63 \%)$ & $0 \cdot 7(0 \cdot 4-1 \cdot 4)$ \\
conversion & $25 / 32(78 \%)$ & $7 / 22(32 \%)$ & $2 \cdot 5(1 \cdot 3-4 \cdot 7)$ \\
Recent onset & $11 / 16(69 \%)$ & $21 / 38(55 \%)$ & $1 \cdot 2(0 \cdot 8-1 \cdot 9)$ \\
Preceding life event & $23 / 24(96 \%)$ & $9 / 30(30 \%)$ & $3 \cdot 2(1 \cdot 8-5 \cdot 6)$ \\
Good recovery at discharge & (grade 0 or 1) & & \\
\hline
\end{tabular}

and more than a year in 12 patients. Nineteen patients were older than 40 at the time of admission (male:female $=1 \cdot 0: 2 \cdot 8$ ). In 13 of these patients the onset of symptoms was recent. Six of these 13 patients had had conversion symptoms earlier in life.

At follow up, two patients (4\%) were found to have developed a neurological disorder that could be related to the initial episode. One 71 year old female patient developed an infarct in the territory of the left middle cerebral artery 2.5 months after an acute but bizarre and transient paralysis of the right foot. She had never had such symptoms before. The other patient (a man aged 43) presented with ataxia and showed grotesque posturing of extremities that was decreased by distraction. He had been admitted to the hospital before with similar symptoms. Multiple sclerosis was considered highly probable after a clinical relapse two months later. At that time CSF and MRI findings were abnormal; these investigations had not been performed before.

Table 2 shows the subsequent course of the remaining 54 patients. Thirty two patients $(59 \%)$ had fully recovered on follow up (grade $0 ; 23$ patients) or had only minor symptoms that did not interfere with lifestyle (grade 1 ; nine patients). The other $22(41 \%)$ patients continued to be more or less disabled by the original symptoms (grades 2-5). Of these 22 patients, 15 were still regularly seeing medical specialists. Overall, there had been few changes after the period in hospital.

Table 3 shows the influence of certain characteristics on outcome. In patients older than 40 years the degree of independence was less good $(42 \%)$ than in younger patients $(69 \%)$, but the difference was not statistically significant. Patients with a recent onset had a good outcome 2.5 times as often as those with a longer history (relative risk 2.5 ; $95 \%$ confidence interval (95\% CI) $1 \cdot 3-4 \cdot 7)$. If the conversion disorder had been preceded by an important life event, the outcome was slightly better $(69 \%)$ than otherwise $(55 \%)$. The strongest predictive factor was the condition of the patient on discharge. If the patient had improved during stay in hospital to grade 0 or 1 on the Oxford handicap scale, the condition at follow up was still good in $96 \%$ of the patients; only $30 \%$ of the patients with major deficits on discharge had a good outcome on follow up (relative risk $3 \cdot 2 ; 95 \%$ CI $1 \cdot 8-5 \cdot 6$ ).

By multivariate analysis we found that a profound improvement at discharge is such a strong predictive factor that no other characteristic carried additional prognostic information. The effect of a recent onset of the conversion disorder was strongly linked to that of a good condition at discharge: of the 24 patients who had recovered during their stay in hospital the onset had been shortly before in 22. In the 30 patients who did not improve during a stay in hospital the only factor that had some additional predictive value was age. None of the 10 patients older than 40 years had a good long term outcome $v$ nine of the 20 patients younger than 40 years. 


\section{Discussion}

Two main conclusions emerge from our follow up study in a cohort of 56 patients with a more or less stable (not paroxysmal) conversion disorder: neurological disease only rarely emerges later, and recovery is not to be expected if improvement has failed to occur during the initial period in hospital.

In previous follow up studies neurological disorders were eventually diagnosed more often (13-34\%). ${ }^{1-7}$ Comparison between series from different centres is difficult for several reasons. Firstly, the distinction between structural and emotionally determined disorders requires considerable experience with both categories. Among the many pitfalls are apraxia, focal dystonia, and combinations of organic deficits and conversion disorder; the two mistakes in our series were in the last category. Modern imaging techniques may help in making the distinction in some cases but may also complicate matters by showing harmless anatomical variants such as arachnoid cysts. Secondly, the association between conversion disorder and subsequent neurological disease may be coincidental, the more so if the interval between the two episodes is long. Thirdly, we excluded patients with paroxysmal disorders and patients in whom known organic disease was complicated by conversion disorder; such combinations are particularly difficult to interpret. We eliminated this problem by studying only patients with supposedly "pure" conversion disorder, diagnosed on the basis of negative neurological and often neuroradiological findings on the one hand and positive psychopathology or bizarre disturbances on the other. Because of these selection criteria a high diagnostic accuracy can be anticipated.

Our follow up study shows that a good outcome of patients with a conversion disorder, which occurred in $59 \%$, depends heavily on whether improvement does occur within the initial period in hospital. The factors age and preceding life event were subordinate. Patients with a recent onset of the conversion disorder were most likely to improve during a stay in hospital. We also found that most patients with chronic deficits kept consulting medical specialists.

Prognosis in this study may be worse than for conversion disorder in general because we studied a group of patients who had been referred to a university hospital. The worst outcome was found in patients who had not improved during admission and were also older than 40 years. A limitation of our study is that patients lacked detailed psychiatric assessment at follow up. Such data are required to determine whether a psychiatric difference exists between patients with good outcome and those with long term disability. It is also not known what effect psychiatric intervention may have in this condition. Nevertheless a stay in hospital alone, with a regime of positive reassurance and exercises, was beneficial in 24 of the 56 patients. Consultative help by a psychiatrist is often difficult, because most patients experience their deficits as purely somatic in nature and reject even the most subtle suggestion that emotional factors might have contributed to their weakness or disordered perception.

We are grateful to Dr A Algra for his help with data analysis.

1 Watson CG, Buranen CH. The frequency and identification of false positive conversion reactions. $\mathcal{F}$ Nerv Ment Dis 1979;167:243-7.

2 Gatfield PD, Guze SB. Prognosis and differential diagnosis of conversion reactions. Diseases of the Nervous System 1962;23:623-31.

3 Slater ETO, Glithero E. A follow-up of patients as suffering from "hysteria". $\mathcal{F}$ Psychosom Res 1965;9:9-13.

4 Raskin M, Talbott JA, Meyerson AT. Diagnosis of conversion reactions. $尹 A M A$ 1966;197:102-6.

5 Stefansson JG, Messina JA, Meyerowitz S. Hysterical neurosis, conversion type: clinical and epidemiological considerations. Acta Psychiatr Scand 1967;53:119-38.

6 Ford CV, Folks DG. Conversion disorder: an overview. Psychosomatics 1985;26:371-83.

7 Lazare A. Current concepts in psychiatry; conversion disorders. N Engl F Med 1981;305:745-8.

8 Barham Carter AB. The prognosis of certain hysterical symptoms. BMF 1949;1:1076-9.

9 Hafeiz HB. Hysterical conversion: a prognostic study. $\mathrm{Br} \mathcal{F}$ Psychiatry 1980;136:548-51.

10 Bamford JM, Sandercock PAG, Warlow CP, Slattery J. Interobserver agreement of the assessment of handicap in stroke patients. Stroke 1989;20:828. 